\title{
B lymphocyte antigen receptor signaling: initiation, amplification, and regulation
}

\author{
Thomas A. Packard and John C. Cambier*
}

\author{
Address: Integrated Department of Immunology, University of Colorado School of Medicine \& National Jewish Health, 1400 Jackson St, \\ Denver, CO 80206 \\ *Corresponding author: John C. Cambier (cambierj@njhealth.org) \\ Fl000Prime Reports 2013, 5:40 (doi:10.12703/P5-40) \\ This is an open-access article distributed under the terms of the Creative Commons Attribution-Non Commercial License \\ (http://creativecommons.org/licenses/by-nc/3.0/legalcode), which permits unrestricted use, distribution, and reproduction in any medium, \\ provided the original work is properly cited. You may not use this work for commercial purposes. \\ The electronic version of this article is the complete one and can be found at: http://f $1000 . c o m /$ prime/reports/b/5/40
}

\begin{abstract}
B lymphocytes and their differentiated daughters are charged with responding to the myriad pathogens in our environment and production of protective antibodies. A sample of the protective antibody produced by each clone is utilized as a component of the cell's antigen receptor (BCR). Transmembrane signals generated upon antigen binding to this receptor provide the primary directive for the cell's subsequent response. In this report, we discuss recent progress and current controversy regarding $B$ cell receptor signal initiation, transduction and regulation.
\end{abstract}

\section{Introduction}

B cells are central components of adaptive immunity, responding to pathogens by proliferation, differentiation and production of antibodies. B cells also function in presentation of antigen to $\mathrm{T}$ cells and secretion of regulatory cytokines and chemokines. Like T cells, they express highly variable and clonally restricted antigenbinding receptors, the specificity of which is determined by immunoglobulin variable region gene rearrangement. The development and function of the B cell is primarily affected by signaling via their $B$ cell antigen receptor (BCR).

An important and controversial topic in the B cell field is the initiation of BCR signaling. In most cases, cell-surface receptors signal via ligand-induced subunit oligomerization, conformational changes, or a combination of these. These receptor/ligand interactions have conformational limitations, likely preserving specificity through a process of coevolution. In contrast, BCR ligands are incredibly diverse and it is imperative to accommodate and discriminate a much broader range of ligand affinity and presentation than other receptors. Put another way, B cell effector function-including secretion of antibody critical to immunity-relies on the ability of the repertoire of BCRs to respond to every possible epitope, in diverse physical contexts, derived from an array of pathogens that are limited only by evolution. As the immune response continues, the pathogen may attempt to evade by modifying antigens, and B cells must keep up with these minor modifications, while also increasing the receptor affinity of the responding B cells. This diversity of ligand/ receptor affinity, orientation, and presentation makes it difficult to resolve a clear mechanism of BCR signal initiation. Thus, many groups have proposed alternative mechanisms of signal initiation and amplification to complement, or dispute, the long established model that simple aggregation of receptors is sufficient to initiate signaling. Here we discuss recent progress and points of contention related to BCR initiation and function.

\section{Overview of BCR signaling}

The BCR is composed of membrane-bound immunoglobulin (mIg) non-covalently associated with a disulfidelinked heterodimer of CD79a $(\operatorname{Ig} \alpha)$ and $C D 79 b(\operatorname{Ig} \beta)$ [1-4] (see Figure 1). Following ligation of the mIg, signals are transduced across the plasma membrane, leading to phosphorylation of the immunoreceptor tyrosine-based activation motif (ITAM) contained in the cytoplasmic tails of the CD79a and $b[1,2,5-7]$. The kinase primarily 
Figure I. B cell receptor signaling and regulation. Upper panel B cell activation

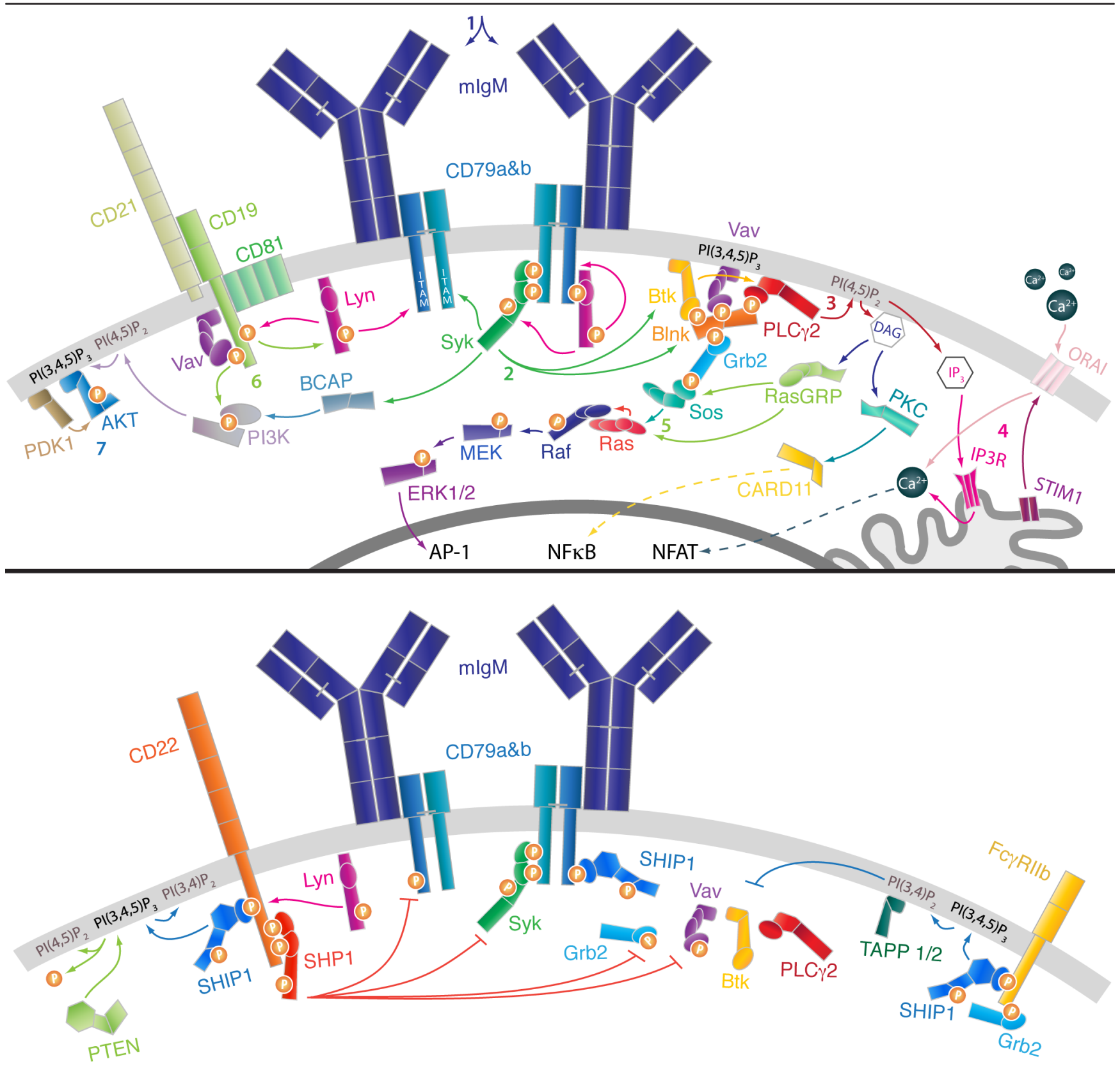

Upon ligation of the BCR (I), ITAMs become phosphorylated via activity of SFKs (such as Lyn) and Syk. Syk and SFKs then phosphorylate signalosome components (2). The signalosome is associated with CD79a non-ITAM phosphotyrosine residues via binding of the adaptor protein Blnk (not illustrated). Activated Btk phosphorylates PLC $\gamma 2$, which in turn cleaves the phosphoinositide $\mathrm{PI}(4,5) \mathrm{P}_{2}$, releasing $\mathrm{IP}_{3}$ into the cytosol and forming $\mathrm{DAG}(\mathbf{3})$. IP 3 binds IP3R in the endoplasmic reticulum, releasing $\mathrm{Ca}^{2+}$ into the cytoplasm. The decrease in endoplasmic reticulum $\left[\mathrm{Ca}^{2+}\right.$ activates STIMI, which binds ORAl in the plasma membrane, forming the CRAC channel and allowing for the influx of extracellular $\mathrm{Ca}^{2+}$ ions (4). RasGRP and protein kinase $\mathrm{C}$ (PKC) are activated by binding DAG, and feed into the MEK/MAP kinase (5) and NFKB activation pathways, respectively. CDI9 plays an important role in amplifying the BCR signal via processive activation of $\mathrm{Lyn}$, and activation of PI3K (6). Along with the recruitment of $\mathrm{PH}$ domain-containing signalosome components, the accumulation of $\mathrm{PI}(3,4,5) \mathrm{P}_{3}$ drives activation of Akt (7). Lower panel B cell deactivation: Lyn phosphorylates immunoreceptor tyrosine-based inhibition motifs (ITIMs) in CD22 and FC $\gamma$ RIllb. These ITIMs activate SHPI and SHIPI, which function to inhibit BCR signaling. The protein phosphatase SHPI has many substrates, including CD79, Syk, Grb2, and Vav, as well as others not shown. Additionally, ITIMs and mono-phosphorylated ITAMs can activate the lipid phosphatase SHIPI. SHIPI hydrolyzes the phosphate at position 5 of $\mathrm{PI}(3,4,5) \mathrm{P}_{3}$, while $\mathrm{PTEN}$ removes that at position 3 . This decrease in $\mathrm{PI}(3,4,5) \mathrm{P}_{3}$ concentration results in the disassociation of many PH domain-containing molecules, inhibiting signalosome assembly and downstream signaling. Illustrated structures not to scale, references in text. 
responsible for this phosphorylation is thought to be a Src-family kinase (SFK): particularly, Lyn, which is the predominant SFK expressed in B cells [8]. Phosphorylation of ITAMs leads to SFK binding by Src-homology 2 (SH2) domains and the upregulation of kinase activity [7]. Dual phosphorylation of ITAM tyrosines leads to Syk binding via its tandem SH2 domains [9]. This binding results in the activation and phosphorylation of Syk $[10,11]$.

Once Syk is activated, the BCR signal is propagated via a group of proteins associated with the adaptor protein B-cell linker (Blnk, SLP-65), which has been referred to as a signalosome [12]. Blnk binds CD79a via non-ITAM tyrosines and is phosphorylated by Syk [13]. PhosphoBlnk serves as a scaffold for the assembly of the other components, including Bruton's tyrosine kinase (Btk), Vav 1, and phospholipase C-gamma 2 (PLC $/ 2$ ) [14]. Btk, Vav 1, and PLC $\gamma 2$ contain pleckstrin-homology (PH) domains that bind lipid phosphoinositides. These phosphoinositides are enriched in the inner leaflet of the plasma membrane and are important for the propagation of multiple signaling pathways. Phosphatidylinositol 3,4,5-triphosphate $\left(\mathrm{PI}(3,4,5) \mathrm{P}_{3}\right)$ is the product of the phosphorylation of $\mathrm{PI}(4,5) \mathrm{P}_{2}$ at position three by phosphoinositide-3-kinase (PI3K). $\mathrm{PI}(3,4,5) \mathrm{P}_{3}$ is a critical second messenger in BCR signaling and is the specific target of lipid phosphatases that regulate signaling.

Following their recruitment by Blnk, Btk phosphorylates PLC $\gamma 2$, which in turn cleaves the phosphoinositide $\mathrm{PI}(4,5) \mathrm{P}_{2}$, generating $\mathrm{IP}_{3}$ and DAG $[15,16]$. IP 3 binds the IP3 receptor (IP3R) in the membrane of the endoplasmic reticulum, resulting in the release of the intracellular stores of $\mathrm{Ca}^{2+}$ ions. This reduction in calcium stores activates calcium-release-activated channels, which allow the influx of extracellular calcium ions $[17,18]$. DAG binds to Ras guanyl nucleotide-releasing protein (RasGRP) as well as the classical members of the protein kinase $\mathrm{C}$ family, such as $\mathrm{PKC} \beta$ in $\mathrm{B}$ cells promoting their activity [19-21].

Distal from these events, BCR signaling becomes quite branched, activating multiple kinase cascades (e.g. Erk/ MAP kinases) and guanine nucleotide exchange factors (e.g. Ras/Raf). The consequences of these signals include the translocation of transcription factors (e.g. NFkB, AP-1, and NFAT); the net result of these processes drives activation of the $\mathrm{B}$ cell, antigen presentation, cytokine production, cell proliferation and differentiation.

These activating signals are necessary to initiate responses against antigens with pathogenic potential. Regulating these responses, as well as silencing autoreactive B cells, are multiple receptors and coupled pathways mediated by phosphatases. Key regulators of proximal BCR signaling include the SH2 domaincontaining phosphatase 1 (SHP1), a protein tyrosine phosphatase, as well as SH2 domain-containing inositol $5^{\prime}$-phosphatase 1 (SHIP1) and phosphatase and tensin homolog (PTEN), lipid phosphatases. Multiple studies have shown that disruption of negative regulatory circuitry can result in subversion of tolerance mechanisms and autoimmunity [22-25].

Together, BCR signaling and its regulation represent complex and dynamic fields of study. For the sake of brevity, we will focus this review on a few of the major recent advances in the contentious area of BCR signal initiation.

\section{Initiation of signaling}

The definitive requirements for BCR engagement, minimally sufficient to initiate signaling, remain controversial. Additionally, these requirements may differ depending on the physical context of the antigenic epitope. B cells can recognize an antigen in soluble and immobilized forms, such as adsorbed onto or embedded in the plasma membrane of another cell, bacterium or virus. In the case of free soluble antigen, crosslinking of two or more BCRs seems to satisfy the minimal requirements for induction of a detectable downstream signal, whereas monovalent soluble ligands do not $[26,27]$. In contrast, monovalent membrane-bound antigens can reportedly induce conformational alterations in the BCR that initiate association with neighboring BCR, and this can lead to signaling [28]. Both of these signal initiation models coalesce in the idea that two or more BCRs become closely associated following ligand binding, allowing for transactivation via SFK and Syk.

Still others propose that it is not aggregation but rather disassociation of preformed oligomeric BCR complexes that releases the receptors from an inhibited state and triggers signaling [29-33]. Reth and colleagues propose a disassociation activation model in which resting B cells have preaggregated BCR that are inhibited via methyltransferase activity and Syk serine kinase activity [31,32]. This model proposes that following ligand binding, BCRs move from "closed"-monomeric or oligomeric states to an "open" cluster conformation that initiates positive signaling. The proponents of this model argue that the flexibility of the hinge in mIg and variability of antigen binding would result in inefficient activation via traditional crosslinking due to steric requirements for signaling, describing this incongruity of antigen/BCR as an "unsolved problem" of clonal selection [30,33]. However, there are two key problems with this 
argument: firstly, no orientational requirements have been described for the induction of BCR signaling, thus they may not exist, and secondly, the hypothesis fails to account for the diversity of the BCR repertoire. The first counterpoint is that flexible $\mathrm{mIg}$, and non-covalently associated CD79-in the round-likely have a diverse assortment of signaling competent orientations. As evidence against steric restriction of the BCR signal consider signaling by intact monoclonal antibodies; it was demonstrated decades ago that monoclonal antibodies recognizing spatially distinct IgM epitopes can induce signaling [34]. If there existed a strict orientational requirement for BCR signal, some or most of these antibodies should be incapable of replicating this orientation and inducing signaling. The second argument of clonal selection and repertoire is simple: the clonal selection theory predicts that the clones capable of responding to an antigen do respond. Thus, clonal selection is a tautology that is self-evident as responding B cells express a BCR capable of signaling regardless of the mechanism of antigen engagement employed.

Other arguments against initiation via aggregation include observations that BCRs exist in preformed oligomers, as shown by native gel electrophoresis [29]. It is likely that BCRs are clustered near each other in highly ordered areas of the plasma membrane, which would explain their apparent association in low-detergent conditions. However, if they were truly oligomers, this interaction should persist in more harsh detergents, such as the observed association of CD79 with mIg. Additionally, Förster resonance energy transfer (FRET) experiments failed to show evidence for oligomerization prior to stimulation [35]. Perhaps BCRs are simply in organized, quiescent clusters poised to signal upon encountering a aggregating ligand. In any case, preorganization of receptors is not a priori indicative of inhibition, as shown by the pre-ligand-binding assembly domains of tumor necrosis factor receptors [36]. Along with the pre-organization of BCRs, there exists evidence that Syk can be activated by a single dual-phosphorylated ITAM [37-39]. To this end, we completely agree. However, this argument is downstream of signal initiation, as either the ITAM must first be phosphorylated, or SFKs and Syk must be activated, subsequently phosphorylating ITAMs. Thus, we discover a "catch-22" in which at least one ITAM must first be dually phosphorylated before Syk can be activated. As SFKs are the likely candidate for this activity, we think the aggregation model allows for the most efficient recruitment of a nearby SFK to drive this activation. Together, most researchers in the field of antigen receptor signaling are in agreement that BCR crosslinking is sufficient to induce signaling, and is the model that best fits current evidence.
Responses induced by different physiochemical forms of antigen may vary in their requirement for proximal signaling effectors. Recent work by Mukherjee et al. suggested that monovalent antigen induction of BCR signaling is dependent on SFKs, whereas SFKs play a less critical role in responses to multivalent antigens [40]. This is in keeping with previous findings using SFK knockout models, suggesting that the Syk tyrosine kinase may be sufficient to initiate signaling in response to multivalent antigens, mediating phosphorylation of receptor ITAMs $[8,41]$. The authors employed in silico modeling to predict the differential roles of Syk and SFKs in responses to multivalent antigens that induce clustering or to homogenous, "monovalent" antigens. These models predict that Syk is critical for BCR signaling via positive feed-forward functions and is able to compensate for SFK deficiency when the stimulating antigen is sufficiently avid. The model's predictions were interrogated by in vitro experiments measuring responses in the presence of Syk and SFK pharmacologic inhibitors. The results of these experiments support the model, though interpretations are compromised somewhat by use of the MD4 system: MD4 B cells are capable of signaling in response to soluble "monovalent" hen egg lysozyme (HEL) in the absence of inhibitors [40,42]. This appears to be a unique property of HEL, as others have demonstrated that monovalent soluble antigens are incapable of inducing signaling [27]. Indeed, with the exception of HEL, previous studies demonstrate that monovalent antigen-induced signaling depends on antigen adsorption to lipid membranes [28]. An explanation of the ability of "monovalent" HEL to induce signaling probably lies in the highly charged nature of HEL, and, likely, rapid spontaneous multimerization, or adsorption on cell surface carbohydrates. Decades of studies indicate that truly monovalent soluble antigens (e.g. monovalent Fab fragments of anti-BCR antibodies) do not induce detectable signaling. Nonetheless, the findings of Mukherjee et al. support the concept that responses to paucivalent antigens are more dependent on SFKs than responses to high avidity antigens, confirming the authors' general predictions.

\section{Signal amplification by CD 19}

CD19, a B cell-restricted membrane glycoprotein, functions both as an accessory in BCR signaling and, when associated with CD21, as a BCR co-receptor for complement C3dg fragments. Recent findings by Depoil et al. indicate that CD19 is uniquely required for responses to membrane-adsorbed antigens [43]. The requirement for CD19 in this response may be related mechanistically to the apparent requirement for SFK in BCR signaling induced by low-avidity antigens [40]. It seems likely that the forward-feeding mechanism of $\mathrm{CD} 19$ as both a 
substrate and processive activator of SFKs may provide amplification of SFK activity critical to sustain cell activation when BCR stimulation is suboptimal [44]. Thus, experimental approaches towards understanding minimal thresholds of BCR stimulation should consider requirements for SFKs and CD19, due to their complementarity.

Interestingly, Mattila et al. recently demonstrated that spontaneous BCR signaling as a result of cytoskeletal disruption is dependent on CD19 and CD81 [45]. The authors use superresolution microscopy (dSTORM) to demonstrate the existence of BCR in preformed "nanoclusters" that associate with Syk upon antigen stimulation, and higher level clustering of BCR induced by anti-Ig antibodies. Despite decades of knowledge that the cytoskeleton affects BCR signaling, the advent of advanced imaging techniques has allowed for a more refined understanding of these mechanisms. The cytoskeleton acts both in organizing and immobilizing BCRs in the resting cell, as well as amplifying signaling by allowing for B cell spreading and synapse formation. These advanced techniques and concepts are reviewed in excellent detail by Harwood \& Batista [46].

Further, CD19 and CD81 are shown to be dispensable for the initiation of signaling in response to soluble, multivalent antigens. These latter results seem inconsistent with previous reports that suggested a critical role for CD19 in the activation of PH domain-containing signaling intermediaries. However, this discrepancy may be explained by the redundant action of $\mathrm{B}$-cell adaptor for phosphoinositide-3-kinase (BCAP) in activation of $\mathrm{PI} 3 \mathrm{~K}$, allowing for the propagation of the BCR signal in the absence of CD19 $[47,48]$. Thus, CD19 may be critical for signaling in response to low-avidity antigens because it enhances SFK and PI3K activation, though in response to high-avidity antigens, it may be redundant with the activity of Syk and BCAP.

\section{Signal modulation}

As well as having differing antigen avidity requirements for the initiation of signaling, Syk and SFKs play different roles in signal propagation. Syk appears completely positive, both in its forward-feeding amplification of ITAM and auto-phosphorylation, as well as activation of downstream components. By contrast, the SFK Lyn activates both positive and negative regulators of BCR signaling, such as CD22, Fo $\gamma$ RIIb, SHP1 and SHIP1 [49]. Recent studies suggest that by toggling between monoand dual-phosphorylated states, ITAMs drive Sykmediated activation versus Lyn-mediated inhibitory signaling. Indeed, in chronically antigen-stimulated anergic B cells, CD79a is monophosphorylated, driving chronic activation of inhibitory SHIP1 signaling [24,50]. This plays a role in preventing activation of anergic B cells.

SHIP1 and SHP1 have recently been shown to play an additional role in B cells, modulating BCR signaling in the germinal center where B cells engage in the somatic mutation of their BCR, and those with resultant increased affinity for antigen are selected for survival and class switching. These phosphatases are upregulated in germinal center B cells and oppose positive BCR signaling at differing levels throughout the cycle of these highly proliferative cells. As a net result of this signal dampening, cells bearing higher affinity receptors are more competitive, leading to affinity maturation $[51,52]$.

The delicacy of the balance of positive and negative signaling is also demonstrated by the effects of altering Lyn levels, as both under and over-expression results in autoimmune phenotypes [53,54]. Other SFKs expressed by B cells, e.g. Fyn, have been demonstrated to have only activating signaling qualities, while Blk is localized on endoplasmic reticulum structures where it appears to regulate IP3 receptor function $[55,56]$. These observations illustrate an important role for Lyn in tolerance, while Fyn and Syk are more important as signaling intermediaries in cell activation.

Underscoring the importance of regulating signals transduced by the BCR is the fact that a high proportion of circulating B cells are autoreactive [57]. Many of these self-specific cells are probably silenced by virtue of ignorance because their autoantigens are monovalent or in low abundance and therefore do not induce signaling. Multivalent autoantigens may, by inducing chronic signaling, render specific B cells anergic. Two recent studies bear on the status of these potentially autoreactive cells. The first, by Zikherman, Parameswaran \& Weiss, shows that in specific-pathogen-free mice, a significant proportion of mature naïve $\mathrm{B}$ cells show evidence of ongoing BCR signaling [58]. Signaling was reported in these studies by GFP expression in B cells from transgenic mice expressing GFP under control of the Nur77 promoter, a transcript driven by early antigenreceptor signaling events. Interestingly, they found that transitional-3 cells, a compartment previously shown to contain anergic cells, were highly enriched for GFP+ cells [59]. Additionally, they found that some GFP+ B cells were present in virtually every compartment, characterized by decreased surface IgM. These findings suggest that a significant proportion of peripheral B cells are stimulated by autoantigens but are spared from activation by regulatory mechanisms. A second study involved analysis of the autoantigen-specific B cells in the normal repertoire of animals expressing an ectopic autoantigen 
(soluble ovalbumin) as well as the natural autoantigen glucose-6-phosphate isomerase (GPI) [60]. The authors demonstrate that in the case of these soluble, presumably monovalent, self antigens, the autoreactive cells appear to be ignorant of antigen in their environment. This is not completely unexpected, and echoes the previously discussed studies: namely, soluble, monovalent antigens fail to trigger BCR signaling. Interestingly, they did find B cell intrinsic tolerance, similar to anergy, when the autoantigen ovalbumin was membranebound, and therefore sufficient to induce a BCR signal.

\section{Summary and conclusion}

To summarize, BCR signaling is initiated via ligation of mIg under conditions that induce phosphorylation of the ITAMs in CD79. This results in the activation of Syk, SFKs, and other signaling intermediaries (i.e. Blnk, Btk, Vav1, PLC 2 2). These are recruited via association with $\mathrm{BCR}$ or PH-domains binding to $\mathrm{PI}(3,4,5) \mathrm{P}_{3}$. While SFKs play roles throughout the process, they appear to be especially necessary in the initiation of signaling by lowavidity antigens. The glycoprotein CD19 is dually important in its amplification of activation of the SFK Lyn, and in activation of PI3K. It is our opinion that this role for CD19 in the amplification of Lyn and activation of PI3K is most critical in examples of low-avidity reactions, whereas, in the case of high-avidity stimuli, Syk and BCAP exhibit compensatory capabilities.

There exist multiple negative regulators of BCR signaling, critical for B cell-intrinsic tolerance. However, recent studies have shown that many potentially autoreactive cells appear functionally naïve, and those that have encountered sufficient antigen to signal can be found in all B cell compartments, and are characterized by lower surface IgM expression.

It is likely that these cells are maintained in the periphery with decreased levels of BCR stimulation and do not become activated due to the "conditional" dominance of inhibitory signaling (i.e. in the steady-state the $\mathrm{B}$ cell is not activated by autoantigen). Though this anergy may seem to flirt with autoimmunity, one could imagine that this is necessary to avoid extensive exploitation of molecular mimicry by pathogens. Further, an increase from normal physiological levels of certain self-antigens is associated with some tumors and other pathophysiologies. Thus, the maintenance of these autoreactive B cells, poised to react to homeostatic disruption, may be important for tumor surveillance and pathogen defense.

We hope we have conveyed the evolving status of principles that govern $\mathrm{B}$ cell antigen receptor signal initiation and its outcome. Signaling is determined by many currently ponderable and imponderable factors. These factors include antigen valency, affinity, concentration, physical context, and chronicity of stimulation; additionally, intrinsic properties of the responding cell, including the relative levels of receptors and signaling intermediaries that function to propagate and regulate signal transmission. Finally, given the complexity of the universe of antigens, the net effect of these factors must be to both respond to pathogenic stimuli and limit these responses, while preventing responses to autoantigens.

\section{Abbreviations}

BCAP, B-cell adaptor for phosphoinositide-3-kinase; BCR, B cell antigen receptor; Blnk, B-cell linker; Btk, Bruton's tyrosine kinase; DAG, diacylglycerol; Fc $\gamma$ RIIb, low-affinity immunoglobulin gamma Fc region receptor II-b; FRET, Förster resonance energy transfer; GFP, green fluorescent protein; GPI, glucose-6-phosphate isomerase; HEL, hen egg lysozyme; $\mathrm{IP}_{3}$, inositol triphosphate; IP3R, inositol triphosphate receptor; ITAM, immunoreceptor tyrosine-based activation motif; ITIM, immunoreceptor tyrosine-based inhibition motif; mIg, membrane-bound immunoglobulin; PI3K, phosphoinositide-3-kinase; $\operatorname{PI}(3,4,5) \mathrm{P}_{3}$, phosphatidylinositol 3,4,5-triphosphate; $\mathrm{PI}(4,5) \mathrm{P}_{2}$, phosphatidylinositol 4,5-bisphosphate; $\mathrm{PH}$, pleckstrin-homology; $\mathrm{PKC}$, protein kinase $\mathrm{C}$; $\mathrm{PLC} \gamma 2$, phospholipase C-gamma 2; PTEN, phosphatase and tensin homolog; RasGRP, Ras guanyl nucleotide-releasing protein; SFK, Src-family kinase; SH2, Src-homology 2; SHIP1, SH2 domain-containing inositol 5'-phosphatase 1; SHP1, SH2 domain-containing phosphatase 1.

\section{Disclosures}

The authors declare that they have no disclosures.

\section{References}

I. Hombach J, Tsubata T, Leclercq L, Stappert H, Reth M: Molecular components of the $B$-cell antigen receptor complex of the IgM class. Nature 1990, 343:760-762.

2. Campbell KS, Cambier JC: B lymphocyte antigen receptors (mlg) are non-covalently associated with a disulfide linked, inducibly phosphorylated glycoprotein complex. EMBO J 1990, 9:44I-448.

3. Gold MR, Matsuuchi L, Kelly RB, DeFranco AL: Tyrosine phosphorylation of components of the $B$-cell antigen receptors following receptor crosslinking. Proc Natl Acad Sci USA I99।, 88:3436-3440.

4. Cambier JC, Pleiman CM, Clark MR: Signal transduction by the B cell antigen receptor and its coreceptors. Annu Rev Immunol 1994, I 2:457-486.

5. Reth M: Antigen receptor tail clue. Nature 1989, 338:383-384.

6. Yao XR, Flaswinkel $H$, Reth $M$, Scott DW: Immunoreceptor tyrosine-based activation motif is required to signal pathways of receptor-mediated growth arrest and apoptosis in murine B lymphoma cells. J Immunol 1995, 155:652-66I.

7. Johnson SA, Pleiman CM, Pao L, Schneringer J, Hippen K, Cambier JC: Phosphorylated immunoreceptor signaling motifs (ITAMs) exhibit unique abilities to bind and activate Lyn and Syk tyrosine kinases. J Immunol 1995, I 55:4596-4603. 
8. Saijo $K$, Schmedt $C$, Su IH, Karasuyama H, Lowell CA, Reth M, Adachi T, Patke A, Santana A, Tarakhovsky A: Essential role of Srcfamily protein tyrosine kinases in NF-kappaB activation during B cell development. Nat Immunol 2003, 4:274-279.

\section{FlOOOPrime \\ RECOMMENDED}

9. Kurosaki T, Johnson SA, Pao L, Sada K, Yamamura H, Cambier JC: Role of the Syk autophosphorylation site and $\mathrm{SH} 2$ domains in B cell antigen receptor signaling. J Exp Med I995, I82:18|5-I823.

10. Rowley RB, Burkhardt AL, Chao HG, Matsueda GR, Bolen JB: Syk protein-tyrosine kinase is regulated by tyrosine-phosphorylated Ig alpha/lg beta immunoreceptor tyrosine activation motif binding and autophosphorylation. J Biol Chem 1995, 270: || $590-1 \mid 594$.

\section{FlOOOPrime}

\section{RECOMMENDED}

II. Shiue L, Zoller MJ, Brugge JS: Syk is activated by phosphotyrosinecontaining peptides representing the tyrosine-based activation motifs of the high affinity receptor for IgE. J Biol Chem 1995, 270: 10498-10502.

\section{FlOOOPrime \\ RECOMMENDED}

12. Fruman DA, Satterthwaite $A B$, Witte ON: Xid-like phenotypes: a B cell signalosome takes shape. Immunity 2000, 13:1-3.

13. Kabak S, Skaggs B], Gold MR, Affolter M, West KL, Foster MS, Siemasko K, Chan AC, Aebersold R, Clark MR: The direct recruitment of BLNK to immunoglobulin alpha couples the B-cell antigen receptor to distal signaling pathways. Mol Cell Biol 2002, 22:2524-2535.

\section{FlOOOPrime RECOMMENDE}

14. Fu C, Turck CW, Kurosaki T, Chan AC: BLNK: a central linker protein in B cell activation. Immunity 1998, 9:93-103.

15. Coggeshall KM, Cambier JC: B cell activation. VIII. Membrane immunoglobulins transduce signals via activation of phosphatidylinositol hydrolysis. J Immunol 1984, I33:3382-3386.

16. Ransom JT, Harris LK, Cambier JC: Anti-lg induces release of inositol 1,4,5-trisphosphate, which mediates mobilization of intracellular Ca++ stores in B lymphocytes. J Immunol 1986, |37:708-7|4.

17. Penna A, Demuro A, Yeromin AV, Zhang SL, Safrina O, Parker I, Cahalan MD: The CRAC channel consists of a tetramer formed by Stim-induced dimerization of Orai dimers. Nature 2008, 456: II $16-120$

\section{FlOOOPrime

RECOMMENDED

18. Hogan PG, Lewis RS, Rao A: Molecular basis of calcium signaling in lymphocytes: STIM and ORAI. Annu Rev Immunol 2010, 28:49I-533

19. Roose JP, Mollenauer M, Ho M, Kurosaki T, Weiss A: Unusual interplay of two types of Ras activators, RasGRP and SOS, establishes sensitive and robust Ras activation in lymphocytes. Mol Cell Biol 2007, 27:2732-2745.

20. Stone JC: Regulation and Function of the RasGRP Family of Ras Activators in Blood Cells. Genes Cancer 20I I, 2:320-334.

21. Guo B, Su TT, Rawlings DJ: Protein kinase $\mathbf{C}$ family functions in B-cell activation. Curr Opin Immunol 2004, 16:367-373.

22. Suzuki A, Kaisho T, Ohishi M, Tsukio-Yamaguchi M, Tsubata T, Koni PA, Sasaki T, Mak TW, Nakano T: Critical roles of Pten in $B$ cell homeostasis and immunoglobulin class switch recombination. J Exp Med 2003, 197:657-667.

\section{FlOOOPrime \\ RECOMMENDED}

23. Maxwell MJ, Duan M, Armes JE, Anderson GP, Tarlinton DM, Hibbs ML: Genetic segregation of inflammatory lung disease and autoimmune disease severity in SHIP-I-I- mice. I Immunol 2011, I86:7164-7175.

FIOOOPrime

24. O'Neill SK, Getahun A, Gauld SB, Merrell KT, Tamir I, Smith MJ, Dal Porto JM, Li QZ, Cambier JC: Monophosphorylation of CD79a and CD79b ITAM motifs initiates a SHIP-I phosphatasemediated inhibitory signaling cascade required for B cell anergy. Immunity 20II, 35:746-756.

25. Pao LI, Lam KP, Henderson JM, Kutok JL, Alimzhanov M, Nitschke L, Thomas ML, Neel BG, Rajewsky K: B cell-specific deletion of proteintyrosine phosphatase Shpl promotes B-la cell development and causes systemic autoimmunity. Immunity 2007, 27:35-48.

\section{FlOOOPrime} RECOMMENDED

26. Metzger $\mathrm{H}$ : Transmembrane signaling: the joy of aggregation. J Immunol 1992, 149:1477-I487.

27. Minguet S, Dopfer EP, Schamel WW: Low-valency, but not monovalent, antigens trigger the B-cell antigen receptor (BCR). Int Immunol 20I0, 22:205-2I2.

\section{FIOOOPrime}

28. Tolar P, Hanna J, Krueger PD, Pierce SK: The constant region of the membrane immunoglobulin mediates B cell-receptor clustering and signaling in response to membrane antigens. Immunity 2009, 30:44-55.

\section{FlOOOPrime}

\section{RECOMMENDED}

29. Schamel WW, Reth M: Monomeric and oligomeric complexes of the B cell antigen receptor. Immunity 2000, I3:5- I4.

\section{FlOOOPrime}

30. Reth M, Wienands J, Schamel WW: An unsolved problem of the clonal selection theory and the model of an oligomeric B-cell antigen receptor. Immunol Rev 2000, 176:10-18.

3I. Heizmann B, Reth M, Infantino S: Syk is a dual-specificity kinase that self-regulates the signal output from the B-cell antigen receptor. Proc Natl Acad Sci USA 2010, 107:18563-18568.

\section{FlOOOPrime}

RECOMMENDED

32. Infantino S, Benz B, Waldmann T, Jung $M$, Schneider R, Reth $M$ : Arginine methylation of the $B$ cell antigen receptor promotes differentiation. J Exp Med 2010, 207:71 I-719.

\section{FlOOOPrime}

33. Yang J, Reth M: The dissociation activation model of $\mathbf{B}$ cell antigen receptor triggering. FEBS Lett 20I0, 584:4872-4877.

34. Leptin M: Monoclonal antibodies specific for murine IgM. II. Activation of B lymphocytes by monoclonal antibodies specific for the four constant domains of IgM. Eur I Immunol 1985, 15:131-13.

\section{FlOOOPrime}

\section{RECOMMENDED}

35. Tolar P, Sohn HW, Pierce SK: The initiation of antigen-induced $B$ cell antigen receptor signaling viewed in living cells by fluorescence resonance energy transfer. Nat Immunol 2005, 6:1168-1176.

\section{FlOOPrime}

\section{RECOMMENDED}

36. Chan FK, Chun HJ, Zheng L, Siegel RM, Bui KL, Lenardo MJ: A domain in TNF receptors that mediates ligand-independent receptor assembly and signaling. Science 2000, 288:235I-2354.

37. Reichlin A, Hu Y, Meffre E, Nagaoka H, Gong S, Kraus M, Rajewsky K, Nussenzweig MC: B cell development is arrested at the immature 
B cell stage in mice carrying a mutation in the cytoplasmic domain of immunoglobulin beta. J Exp Med 200I, 193:13-23.

\section{FlOOOPrime}

38. Rolli V, Gallwitz M, Wossning T, Flemming A, Schamel WW, Zürn C, Reth M: Amplification of $B$ cell antigen receptor signaling by a Syk/ITAM positive feedback loop. Mol Cell 2002, 10:1057-1069.

\section{FlOOOPrime} RECOMMENDED

39. Tsang E, Giannetti AM, Shaw D, Dinh M, Tse JK, Gandhi S, Ho H, Wang S, Papp E, Bradshaw JM: Molecular mechanism of the Syk activation switch. J Biol Chem 2008, 283:32650-32659.

40. Mukherjee S, Zhu J, Zikherman J, Parameswaran R, Kadlecek TA, Wang Q, Au-Yeung B, Ploegh $\mathrm{H}$, Kuriyan J, Das J, Weiss A: Monovalent and multivalent ligation of the $B$ cell receptor exhibit differential dependence upon Syk and Src family kinases. Sci Signal 20I3, 6:ral.

\section{FlOOOPrime}

41. Takata M, Sabe H, Hata A, Inazu T, Homma Y, Nukada T, Yamamura H, Kurosaki T: Tyrosine kinases Lyn and Syk regulate $B$ cell receptor-coupled $\mathrm{Ca2}+$ mobilization through distinct pathways. EMBO J 1994, 13:134I-1349.

42. Kim YM, Pan JY, Korbel GA, Peperzak V, Boes M, Ploegh HL: Monovalent ligation of the $B$ cell receptor induces receptor activation but fails to promote antigen presentation. Proc Natl Acad Sci USA 2006, 103:3327-3332.

\section{FlOOOPrime} RECOMMENDED

43. Depoil D, Fleire S, Treanor BL, Weber M, Harwood NE, Marchbank KL, Tybulewicz VL, Batista FD: CDI9 is essential for $B$ cell activation by promoting $B$ cell receptor-antigen microcluster formation in response to membrane-bound ligand. Nat Immunol 2008, 9:63-72.

\section{FlOOOPrime} RECOMMENDED

44. Fujimoto M, Fujimoto Y, Poe JC, Jansen PJ, Lowell CA, DeFranco AL, Tedder TF: CDI 9 regulates Src family protein tyrosine kinase activation in B lymphocytes through processive amplification. Immunity 2000, 13:47-57.

\section{FlOOOPrime \\ RECOMMENDED}

45. Mattila PK, Feest C, Depoil D, Treanor B, Montaner B, Otipoby KL, Carter R, Justement LB, Bruckbauer A, Batista FD: The actin and tetraspanin networks organize receptor nanoclusters to regulate B cell receptor-mediated signaling. Immunity 2013, $38: 46 \mid-474$

\section{FlOOOPrime}

\section{RECOMMENDED}

46. Harwood NE, Batista FD: The cytoskeleton coordinates the early events of B-cell activation. Cold Spring Harb Perspect Biol 20I I, 3.

\section{FlOOOPrime RECOMMENDED}

47. Okada T, Maeda A, Iwamatsu A, Gotoh K, Kurosaki T: BCAP: the tyrosine kinase substrate that connects B cell receptor to phosphoinositide 3-kinase activation. Immunity 2000, 13:817-827.

\section{FlOOOPrime \\ RECOMMENDED}

48. Aiba Y, Kameyama M, Yamazaki T, Tedder TF, Kurosaki T: Regulation of B-cell development by BCAP and CDI9 through their binding to phosphoinositide 3-kinase. Blood 2008, III:1497-1503.

FlOOOPrime

49. Nishizumi H, Horikawa K, Mlinaric-Rascan I, Yamamoto T: A double-edged kinase Lyn: a positive and negative regulator for antigen receptor-mediated signals. J Exp Med 1998, 187:1343-1348.

\section{FlOOOPrime}

\section{RECOMMENDED}

50. Pao LI, Famiglietti SJ, Cambier JC: Asymmetrical phosphorylation and function of immunoreceptor tyrosine-based activation motif tyrosines in B cell antigen receptor signal transduction. J Immunol 1998, 160:3305-33I4.

51. Khalil AM, Cambier JC, Shlomchik MJ: B cell receptor signal transduction in the GC is short-circuited by high phosphatase activity. Science 2012, 336:1178-1181.

\section{FlOOOPrime} RECOMMENDED

52. Leung WH, Tarasenko T, Bolland S: Differential roles for the inositol phosphatase SHIP in the regulation of macrophages and lymphocytes. Immunol Res 2009, 43:243-25I.

53. Hasegawa M, Fujimoto M, Poe JC, Steeber DA, Lowell CA, Tedder TF: A CDI9-dependent signaling pathway regulates autoimmunity in Lyn-deficient mice. J Immunol 200I, 167:2469-2478.

54. Hibbs ML, Harder KW, Armes J, Kountouri N, Quilici C, Casagranda F, Dunn AR, Tarlinton DM: Sustained activation of Lyn tyrosine kinase in vivo leads to autoimmunity. J Exp Med 2002, 196:1593-1604.

\section{FlOOOPrime}

\section{RECOMMENDED}

55. Horikawa K, Nishizumi H, Umemori H, Aizawa S, Takatsu K, Yamamoto T: Distinctive roles of Fyn and Lyn in IgD- and IgM-mediated signaling. Int Immunol 1999, I I:| 44 I-I 449.

56. Castillejo-Lopez C, Delgado-Vega AM, Wojcik J, Kozyrev SV, Thavathiru E, Wu YY, Sanchez E, Pollmann D, Lopez-Egido JR, Fineschi S, Domínguez N, Lu R, James JA, Merrill JT, Kelly JA, Kaufman KM, Moser KL, Gilkeson G, Frostegård J, Pons-Estel BA, D'Alfonso S, Witte T, Callejas JL, Harley JB, Gaffney PM, Martin J, Guthridge JM, Alarcón-Riquelme ME: Genetic and physical interaction of the B-cell systemic lupus erythematosus-associated genes BANKI and BLK. Ann Rheum Dis 2012, 71:136-I42.

57. Wardemann H, Yurasov S, Schaefer A, Young JW, Meffre E, Nussenzweig MC: Predominant autoantibody production by early human B cell precursors. Science 2003, 30 I:1374-1377.

\section{FlOOOPrime}

\section{RECOMMENDED}

58. Zikherman J, Parameswaran R, Weiss A: Endogenous antigen tunes the responsiveness of naive $B$ cells but not $T$ cells. Nature 2012, 489:160-164

\section{RECOMMENDED}

59. Merrell KT, Benschop RJ, Gauld SB, Aviszus K, Decote-Ricardo D, Wysocki LJ, Cambier JC: Identification of anergic B cells within a wild-type repertoire. Immunity 2006, 25:953-962.

\section{FlOOOPrime} RECOMMENDED

60. Taylor JJ, Martinez RJ, Titcombe PJ, Barsness LO, Thomas SR, Zhang N, Katzman SD, Jenkins MK, Mueller DL: Deletion and anergy of polyclonal B cells specific for ubiquitous membrane-bound self-antigen. J Exp Med 2012, 209:2065-2077. 